\title{
EFEITOS DO ESTRESSE HÍDRICO SOBRE O DESEMPENHO GERMINATIVO DA SEMENTE DE FAVEIRA (Clitoria fairchildiana R.A. Howard. - FABACEAE) DE DIFERENTES TAMANHOS ${ }^{1}$
}

\author{
BRENO MARQUES DA SILVA E SILVA², NELSON MOREIRA DE CARVALHO3
}

\begin{abstract}
RESUMO - Clitoria fairchildiana R. Howard, vulgamente conhecida como faveira, é uma espécie arbórea utilizada na arborização e recomendada para recuperação de áreas degradada, pois é capaz de atuar como adubo verde. No entanto, há poucos estudos básicos para compreender seus atributos ecológicos e fisiológicos. Desse modo, o presente trabalho teve por objetivo estudar as influências do tamanho da semente e de estresse hídrico sobre a germinação das sementes e vigor de plântulas de faveira. Foram usadas sementes pequenas, médias e grandes, postas para germinar em bandejas, com areia, sob condições de umedecimento de $25 \%, 50 \%, 75 \%$ e $100 \%$ da capacidade de retenção de água. A germinação não é afetada pelo tamanho da semente, mas sim pelo vigor, pois as sementes grandes e médias originam plântulas mais vigorosas. Água em excesso reduziu a porcentagem e a velocidade de germinação ao passo que, falta de água, reduziu o crescimento das plântulas.
\end{abstract}

Termos para indexação: germinação, vigor, Leguminosae.

\section{SEED SIZE AND WATER STRESS EFFECTS ON SEED GERMINATION AND SEEDLING VIGOR OF FAVEIRA (Clitoria fairchildiana R.A. Howard. - FABACEAE)}

\begin{abstract}
Clitoria fairchildiana R. Howard, commonly known as faveira, is a widely used tree species in reforestation projects and is also recommended for the recovery of degraded areas, due to the possibility of its use as green manure. However, there are few basic studies to understand its ecological and physiological attributes. Thus, the objective of the present work was to study the influence of seed size and water stress on the seed germination and seedling vigor in faveira. Four repetitions of 25 small, medium, and large seeds were sown in washed and sterilized sand moistened with water to $25,50,75$, and $100 \%$ of its water holding capacity. In accordance with the results, it was concluded that seed germination was not affected by seed size whereas seedling vigor was, since large and medium-sized seeds gave rise to more vigorous seedlings. Water excess reduced total and speed of seed germination whereas lack of water reduced seedling growth.
\end{abstract}

Index terms: germination, vigor, Leguminosae.

\section{INTRODUÇÃO}

Historicamente, no Brasil, a vegetação natural vem sendo suprimida para permitir, principalmente, à expansão

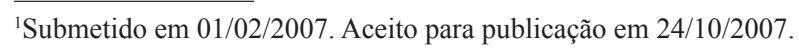

${ }^{2}$ CAPES - Doutorando em Agronomia [Produção e Tecnologia de Sementes] - DPV - FCAV - UNESP Jaboticabal. Avenida Aurora Ferreira Pires da Costa, 2116, 68904-200, Buritizal, Macapá - AP - Brasil. E-mail: das fronteiras agrícola e pecuária. Na maioria das atividades, novas áreas são abertas, quer seja por esgotamento dos solos ou pela necessidade de maior produção (Sampaio, 2000; Silva et al., 2003), assim como, a exploração desordenada

silvabms@hotmasil.com

${ }^{3}$ Prof. Titular Dr. - UNESP-FCAV - DPV. Via de Acesso Prof. Donato Castellane, s/n, 14884-900, Jaboticabal-SP-Brasil. E-mail: nmc@fcav.unesp.br 
dos recursos naturais tem degradado áreas por quase todo o território nacional (Ferreira, 2000), resultando na fragmentação da paisagem e na redução da biodiversidade em várias escalas (Laurance et al., 1998).

Aproximadamente 168 milhões de hectares do território brasileiro são compostos por terras degradadas e marginais, com vocação florestal (Carpanezzi, 1993). Na ocupação florestal destas terras, os plantios são eficazes porque, relativamente à regeneração natural, aceleram o processo de reabilitação (IBM, 1992).

Em reflorestamento, o plantio de mudas é o método mais utilizado, principalmente por permitir a obtenção de um povoamento com densidade inicial bastante uniforme. Por outro lado, a regeneração natural apresenta baixos custos diretos, apresentando, contudo, a desvantagem de ser método demorado, além do que, em condições não favoráveis, pode ser extremamente difícil obter uma regeneração natural satisfatória (Jankovski, 1996). O sistema de regeneração convencional, isto é, com formação de mudas em viveiros, para revegetação de áreas extensas, é oneroso e, muitas vezes, dificulta a recuperação de áreas degradadas (Franco et al, 1992). Uma das alternativas ao plantio de mudas de espécies florestais é o uso de semeadura direta, para recobrir rapidamente grandes áreas com pouco trabalho e baixo custo, pois não precisa de técnicos especializados e estrutura de viveiro (Duryea, 2000; Rodrigues e Gandolfi, 2000), bem como pode ser usado em locais de difícil acesso (Duryea, 2000). Por esses motivos, o método da semeadura direta torna-se mais econômico que o plantio de mudas (D'arco e Mattei, 2000).

De acordo com Mattei et al. (2002) e Meneghello e Mattei (2004), as espécies nativas de timbaúva, canafístula e cedro possuem potencial para serem utilizadas no método de regeneração por semeadura direta, a lanço ou com protetor, em campos abandonados.

Dentre as nativas, Clitoria fairchildinana R. A. Howard, sinonímia $C$. racemosa Lindl., conhecida como faveira, sombreiro ou palheteira, é uma espécie arbórea de médio até grande porte, de frondosa copa com flores atrovioláceas em racemos pêndulos e fruto em legume deiscente, que ocorre, principalmente na Floresta Ombrófila Densa, na Amazônia, em formações secundárias, apresentando nítida preferência por solos férteis e úmidos, ainda que ocorra igualmente em áreas abertas e alteradas (Lorenzi, 1992; Paula e Alves, 1997). Por ser rústica e de rápido crescimento, é igualmente útil nos reflorestamentos heterogêneos destinados à reconstituição da vegetação e recuperação de áreas degradadas (Lorenzi, 1992; Portela et al., 2001). A faveira pode, ainda, atuar na recuperação da fertilidade do solo, pois é capaz de nodular e fixar nitrogênio atmosférico (Carneiro et al., 1998; Fortes, 2000).

Nos últimos anos tem se intensificado o interesse na propagação de espécies florestais nativas, devido à ênfase atual nos problemas ambientais, ressaltando-se a necessidade de recuperação de áreas degradadas e recomposição da paisagem. Entretanto, não há conhecimento disponível para o manejo e análise das sementes da maioria dessas espécies, de modo a fornecer dados que possam caracterizar seus atributos físicos e fisiológicos. Há, também, necessidade de se obter informações básicas sobre a germinação, cultivo e potencialidade dessas espécies nativas, visando sua utilização para os mais diversos fins (Aguiar et al., 1993; Zanon et al., 1997; Araújo Neto et al. 2003).

Dentre os fatores abióticos, a água proporciona o início da germinação, pois a semente deve atingir determinado conteúdo de água para poder germinar, sendo que as mesmas respondem diferentemente a níveis iguais de hidratação. Desta forma, um determinado nível de hidratação pode tanto aumentar como reduzir a germinação, de acordo com Marcos Filho et al. (1987), Borges e Rena (1993) e Cardoso (2004).

As sementes mesófilas requerem elevadas quantidades de água, porém sem alagamento, para o desenvolvimento adequado da germinação das mesmas (Cardoso, 2004). No entanto, para sementes que requerem menos água, recomenda-se utilizar menores quantidades ou remover o excesso de água do substrato para a realização da germinação (Marcos Filho, 1986; Brasil, 1992; Castro et al., 2004). Por outro lado, na falta de água, o processo germinativo pode ser inviabilizado (Borges e Rena, 1993; Carvalho e Nakagawa, 2000; Marcos Filho, 2005).

Em geral, as sementes maiores foram mais nutridas durante o desenvolvimento e, por conseguinte, possuem maior quantidade de substâncias de reserva, sendo assim, potencialmente, as mais vigorosas e capazes de originar plântulas fortes e com maior probabilidade de sobrevivência, principalmente, sob condições adversas de campo, como sob estresse hídrico e sombreamento, de acordo com Popinigis (1977), White e González (1990), Haig e Westoby (1991) e Carvalho e Nakagawa (2000). No entanto, o tamanho da semente tem efeito pronunciado sobre o crescimento inicial de plantas, diminuindo de intensidade à medida que as plantas se desenvolvem (Carvalho e Nakagawa, 2000).

Os efeitos do tamanho das sementes vêm sendo estudados há algum tempo (Carvalho e Nakagawa, 2000; Cardoso, 2004). Desta forma, trata-se, pois, de assunto muito estudado, mas não inteiramente elucidado (Carvalho e 
Nakagawa, 2000; Malavasi e Malavasi, 2001). Desta forma, o presente trabalho teve por objetivo estudar influência do tamanho da semente e do estresse hídrico sobre a germinação e vigor de plântulas de faveira.

\section{MATERIAIS E MÉTODOS}

Vinte árvores matrizes de faveira, selecionadas segundo orientações básicas de Figliolia e Aguiar (1993), localizamse no Parque Zoobotânico de Macapá (0002'21'S, 51 $1^{\circ} 05^{\prime} 35^{\prime}$ 'W), Município de Macapá - AP - Brasil. De acordo com Souto (1994), o clima de Macapá é do tipo Af., segundo a classificação de Koppen. Os frutos maduros, de coloração marrom a castanha, como descrito por Silva et al. (2005), foram coletados diretamente das árvores antes da dispersão, conforme indicações gerais de Figliolia (1995).

Os frutos foram secos a sombra durante 24 horas e, em seguida, torcidos manualmente para promover a abertura e, conseqüentemente, possibilitar a retirada das sementes. Posteriormente, as sementes fora embaladas em sacos de polietileno e, posteriormente, enviadas para as análises físicas e fisiológicas no Laboratório de Sementes - FCAV UNESP Jaboticabal, Jaboticabal - SP - Brasil.

Devido a variação no tamanho das sementes, o lote foi dividido em sub-lotes por meio da estratificação em peneiras de crivos circulares com aberturas de 6, 8, 10, 12, 14, 16, 18 e $20 \mathrm{~mm}$ de diâmetro. Posteriormente, as sementes foram classificadas como pequenas, médias e grande de 12, 14 e 16 $\mathrm{mm}$, respectivamente. Em seguida, foram determinadas as quantidades de sementes por peneira e o peso de 100 sementes das peneiras 12, 14 e $16 \mathrm{~mm}$, de acordo as Regras de Análise de Sementes (Brasil, 1992). Em seguida, determinou-se o teor de água das sementes por meio da secagem de 5 repetições de 20 sementes em estufa a $105^{\circ} \mathrm{C} \pm 3$ durante 24 horas, de acordo com Brasil (1992).

Para obtenção da curva de embebição, foram inicialmente pesadas de 3 repetições de 10 sementes, as quais foram imersas por 1, 3, 6, 12, 24, 36, 48 e 72 horas em solução aquosa de Nistatina $0,2 \%$, para evitar a deterioração por proliferação de fungos, em caixas plásticas, mantidas em $30^{\circ} \mathrm{C}$. Em cada um dos períodos, as sementes foram retiradas da solução, secas superficialmente com papel absorvente e pesadas. Por meio dos valores das porcentagens consecutivas, calculou-se a porcentagem de ganho de água em relação ao peso inicial das sementes, a fim de gerar a curva de embebição, de acordo com o procedimento descrito por Lima et al. (2007).

Para avaliar a influência do tamanho da semente, foram usadas 4 repetições de 25 sementes pequenas, médias e grandes, colocadas em bandejas plásticas $(40 \mathrm{~cm} \times 25 \mathrm{~cm} \times 20 \mathrm{~cm})$, contendo areia lavada, esterilizada e com umedecimento de $25,50,75$ e $100 \%$ da capacidade de retenção de água, determinada de acordo Brasil (1992), mantidas em casa de vegetação, em temperatura ambiente $\left(23 \pm 5,5^{\circ} \mathrm{C}\right)$, com fotoperíodo de 12 horas e $30 \%$ de sombreamento. Durante os 30 dias, diariamente, as bandejas foram pesadas e, adicionalmente, água foi colocada para restabelecer os umedecimentos de 25, 50, 75 e 100\% da capacidade de retenção de água pela areia.

Diariamente, foi registrado o número de plântulas normais, conforme conceito de Brasil (1992). Posteriormente, foram calculados a porcentagem e o índice de velocidade de germinação, de acordo com Maguire (1962). Decorrido 30 dias da semeadura, foram realizadas mensurações para a massa de matéria seca do cotilédone, da raiz e da parte aérea e a razão da parte aérea/raiz e da (parte aérea + raiz)/ cotilédone, de acordo com os procedimentos indicados por Benincasa (2003).

O delineamento experimental utilizado foi o inteiramente casualizado, em esquema fatorial $3 \times 4$, sendo 3 tamanhos de sementes (pequenas, médias e grandes) e 4 níveis de umedecimento da areia $(25,50,75$ e $100 \%$ da capacidade de retenção). Os dados de porcentagem de germinação foram transformados em $(\operatorname{arc} \operatorname{sen} \mathrm{x} / 100)^{0,5}$, para normalização de sua distribuição (Bartlet, 1947). Nas tabelas, foram apresentadas as médias originais de porcentagem de germinação. As análises de variância foram realizadas mediante aplicação do Teste $\mathrm{F}$ ao nível de $5 \%$ de probabilidade e, quando $\mathrm{F}$ foi significativo, as médias das variáveis avaliadas, entre os tamanhos de sementes, foram comparadas pelo Teste de Tukey ao nível de 5\% de probabilidade e, entre as porcentagens de retenção de água, foram realizadas análises por regressão polinomial (Pimentel-Gomes, 1987).

\section{RESULTADOS E DISCUSSÃO}

De acordo com a estratificação por peneira de crivos circulares, as sementes de faveira apresentam sua distribuição entre as peneiras de 8 a $18 \mathrm{~mm}$, sendo que a freqüência com que cada um desses tamanhos ocorre apresenta distribuição normal (Figura 1A). De forma semelhante aos resultados de Cruz et al. (2001), porém para as sementes de jatobá (Hymenaea intermedia Ducke).

As sementes de faveira retidas nas peneiras de perfurações circulares de 0,8 e 1,8 cm de diâmetro foram verificadas ocorrer em porcentagens próximas de zero, o que dificultaria sua exploração comercial, sendo que os tamanhos de maior 

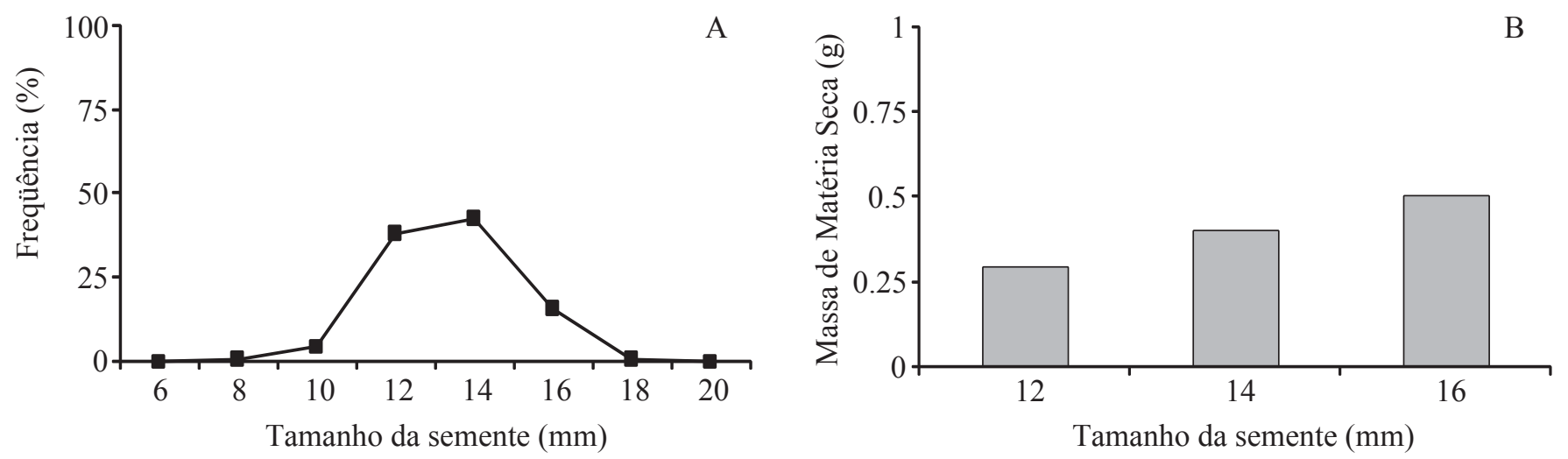

Figura 1.A. Distribuição da porcentagem de sementes faveira entre as peneiras redondas com aberturas de 6, $8,10,12,14,16,18$ e $20 \mathrm{~mm}$ de diâmetro. B. Massa de matéria seca de sementes pequena (12mm), média $(14 \mathrm{~mm})$ e grande $(16 \mathrm{~mm})$ de faveira.

ocorrência, de 12, 14 e 16 mm seriam os tamanhos de maior probabilidade de serem empregados para a produção de mudas em escala comercial (Figura 1A).

O aumento nos tamanhos das sementes de 12 a $16 \mathrm{~mm}$ corresponderam acréscimos na massa seca de sementes de faveira (Figura 1B). De acordo com Ferreira e Torres (2000), comportamento semelhante foi observado em sementes de acácia (Acacia senegal (L.) Willd.).

O teor de água das sementes de faveira foram semelhantes entre os diferentes tamanhos de sementes (Figura2A), assim como, a absorção de água ocorre livremente (Figura 2B), o que é entendido como uma indicação de que as sementes usadas neste experimento não tinham dormência, impermeabilidade do tegumento a água e/ou gases, freqüentemente, encontrada em Fabaceae (Floriano, 2004).

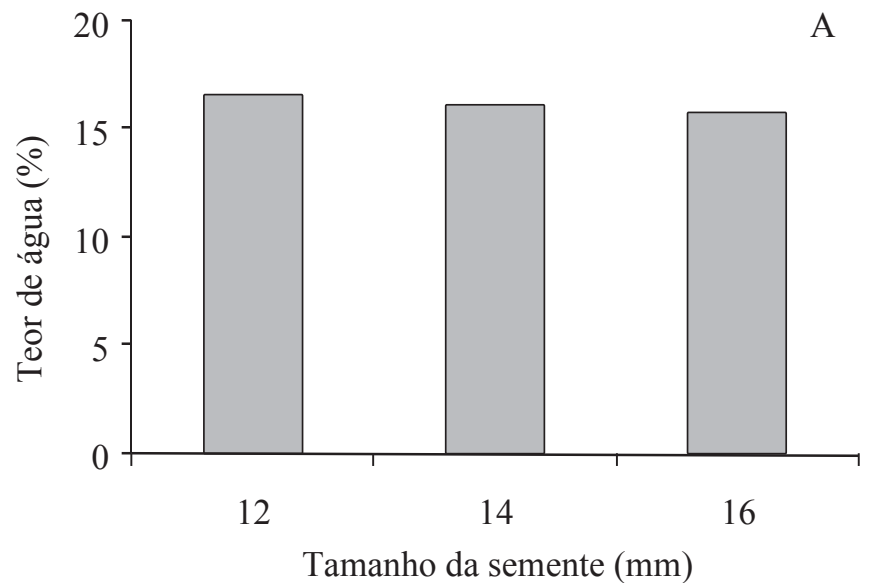

A embebição das sementes de faveira obedecem o padrão trifásico de absorção de água, de acordo com o conceito de Bewley e Black (1994), pois nas primeira 24 horas há rapidamente adsorção de água (fase 1 ou fase log) e, de 24 até 72 horas, há parca absorção de água (fase 2 ou fase estacionária), porém nesta última hora, a semente recomeça absorver água (fase 3) (Figura 2B).

Para porcentagem e índice de velocidade de germinação de sementes de faveira não houve interações significativas entre os níveis de umedecimento da areia e o tamanho da semente, assim como, o tamanho de semente não afetou significativamente tanto a porcentagem quanto o índice de velocidade de germinação (Tabela 1). De acordo com Carvalho (1972) e Nóbrega et al. (1994), as sementes de amendoim apresentam comportamento semelhante. Da

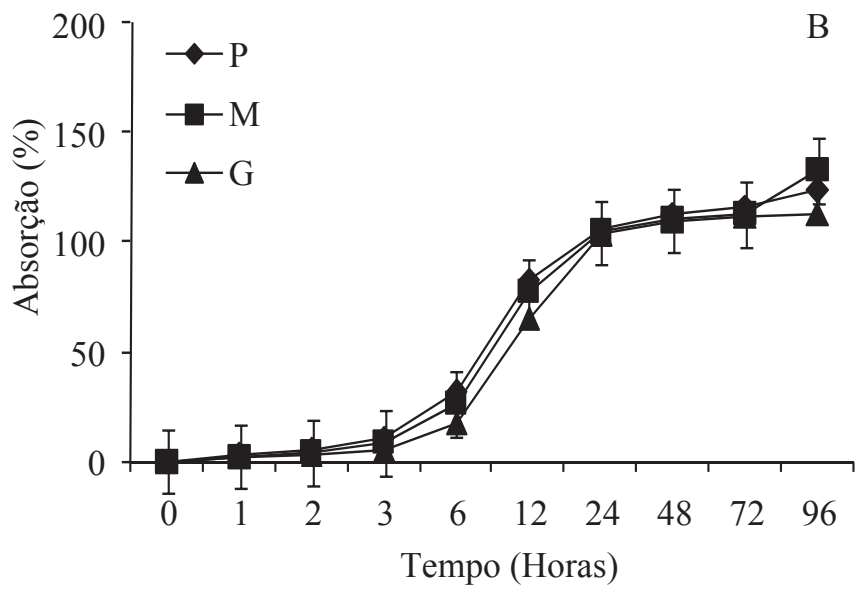

Figura 2. A. Teor de água dos sub-lotes de sementes de faveira de $12 \mathrm{~mm}(\mathrm{P}), 14 \mathrm{~mm}(\mathrm{M})$ e $16 \mathrm{~mm}(\mathrm{G})$. B. Curva de embebição de sementes de pequena $(P)$, média $(M)$ e grande $(G)$ de faveira em Nistatina $0,2 \%$ à $30^{\circ} \mathrm{C}$. 
Tabela 1. Porcentagem de germinação (PG) e índice de velocidade de germinação (IVG) de sementes de pequena $(P)$, média $(M)$ e grande $(G)$ de faveira de independente da capacidade de retenção de água pela areia.

\begin{tabular}{|c|c|c|c|}
\hline Fatores & \multicolumn{3}{|c|}{ Parâmetros } \\
\hline $\begin{array}{l}\text { Tamanho de } \\
\text { semente }(\mathrm{mm})\end{array}$ & $\mathrm{PG}^{0 *}$ & PG $(\%)$ & $\begin{array}{c}\mathrm{IVG}_{1} \text { (Dias } \\
\text { (D) }\end{array}$ \\
\hline $12(\mathrm{P})$ & $72.2 \mathrm{~A}$ & 88.8 & $1.103 \mathrm{~A}$ \\
\hline $14(\mathrm{M})$ & $68.5 \mathrm{~A}$ & 84.3 & $1.049 \mathrm{~A}$ \\
\hline $16(\mathrm{G})$ & $69.4 \mathrm{~A}$ & 85.0 & $1.036 \mathrm{~A}$ \\
\hline DMS (Tukey a 5\%) & \multicolumn{2}{|c|}{6.2522} & 0.0764 \\
\hline $\begin{array}{l}\text { Coeficiente de } \\
\text { variação }(\%)\end{array}$ & \multicolumn{2}{|c|}{10.3342} & 8.3187 \\
\hline
\end{tabular}

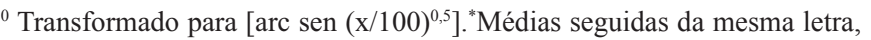
nas colunas, não diferem entre si pelo Teste de Tukey ao nível de $5 \%$ de probabilidade.

mesma forma, foi observado por Ferreira e Torres (2000), para as sementes Acacia senegal (L.) Willd.. Ao contrário, Wetzel (1975) verificou que as sementes pequenas de soja de uma linhagem isogênica (D65-6792) apresentam germinação e vigor inferiores aos de sementes grandes.

Para a porcentagem de germinação, os pontos de máxima respectivos para sementes pequenas, médias e grandes de faveira foram de $43,0 \%, 50,8 \%$ e $53,6 \%$. A partir desses pontos, os índices de velocidade de germinação diminuem quadraticamente, principalmente, com o aumento do umedecimento da areia (Figura 3A). Enquanto, para o índice de velocidade de germinação, os pontos de máxima respectivos para sementes pequenas, médias e grandes de faveira foram de $49,6 \%, 50,6 \%$ e 54,8\%. A partir desses pontos, as porcentagens de germinação diminuem quadraticamente, principalmente, com o aumento do umedecimento da areia (Figura 3A). Provavelmente, a condição de anaerobiose devido ao umedecimento de $100 \%$ de retenção da areia foi à causa da redução do desempenho germinativo das sementes de faveira, conforme Popinigis (1977).

Em 25\% de capacidade de retenção de água pela areia, não houve diferenças significativas para massa seca da raiz, da parte aérea e do cotilédone de plântulas oriundas de sementes pequenas, médias e grandes de faveira. No entanto, em 50, 75 e $100 \%$, as sementes médias e grandes proporcionam maior acúmulo massa seca da raiz, parte aérea e cotilédone nas plântulas de faveira, exceto, a produção de massa seca raiz por plântulas desenvolvidas em areia $100 \%$ da capacidade de retenção de água (Tabela 2). A anoxia e/ou hipoxia proporcionado pelo umedecimento de $100 \%$ tornou-se uma barreira e, possivelmente, selecionou a germinação das sementes de faveira mais vigorosas,
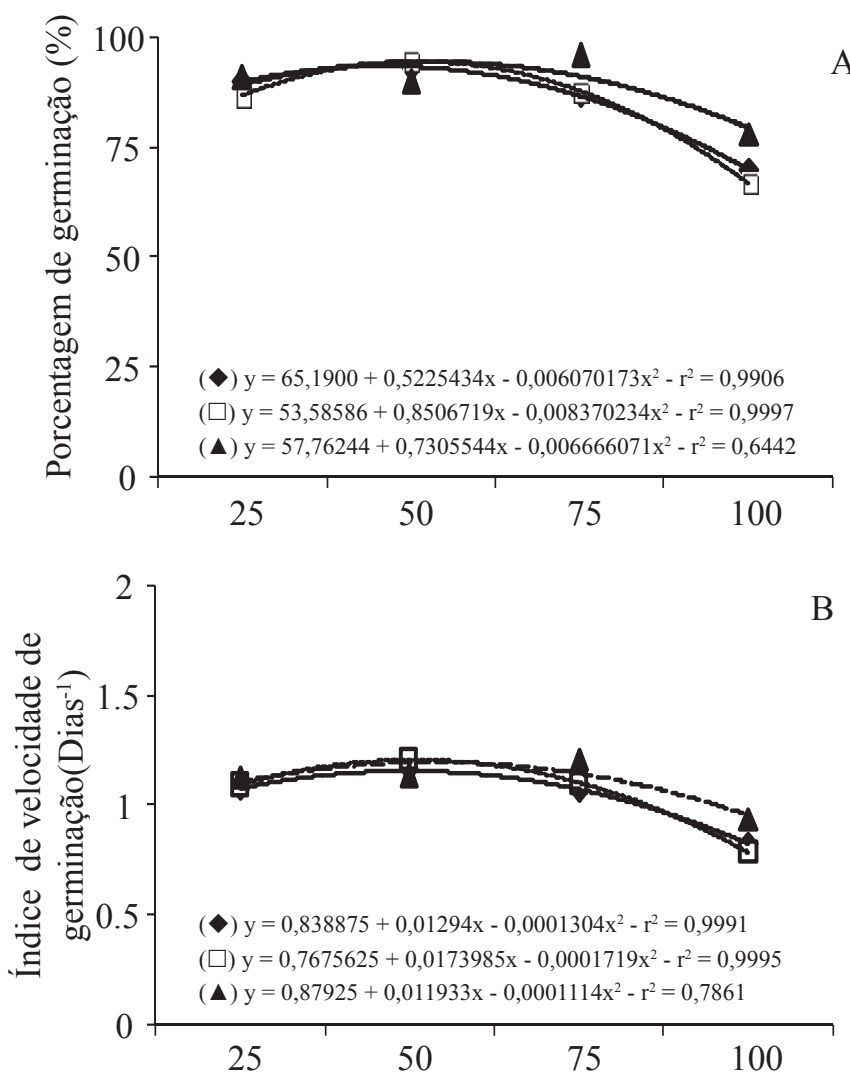

Capacidade de retenção de água (\%)

Figura 3. A. Porcentagem de germinação. B. Índice de velocidade de germinação de sementes de faveira das peneiras de $12 \mathrm{~mm}(\Delta), 14 \mathrm{~mm}(\square)$ e $16 \mathrm{~mm}(\diamond)$ em areia umedecida com $25,50,75 \mathrm{e}$ $100 \%$ da capacidade de retenção de água.

pois sementes de alto vigor são potencialmente mais capazes de resistir a estresses ambientais (Braccini et al., 1999; Carvalho e Nakagawa, 2000).

O que se constata é que, sob níveis de 75 e $100 \%$ de umedecimento, a conteúdo de matéria seca de raiz e parte aérea da plântula como um todo, aumentou acentuadamente para as classes de tamanhos das sementes, indicando que, à medida que aumentou o nível de hipoxia, somente as sementes mais vigorosas conseguiram germinar (Tabela 2). Por outro lado, a baixa disponibilidade de água em $25 \%$ não foi capaz de restringir a germinação de sementes de faveira menos vigorosas dentre as avaliadas (Tabela 1), porém prejudicou significativamente o desenvolvimento das plântulas, pois nesta condição observou-se um menor acúmulo de matéria seca para os parâmetros avaliados entre 
Tabela 2. Massa de matéria seca de raiz $(\mathrm{R})$, parte aérea $(P A)$, parte aérea + raiz $(P A R)$ e cotilédone $(C)$ de plântulas de faveira, oriundas de sementes de pequena $(P)$, média $(M)$ e grande $(G)$ nas capacidades de campo de 25 , 50,75 e $100 \%$ após 30 dias de semeadura.

\begin{tabular}{|c|c|c|c|c|}
\hline \multicolumn{5}{|c|}{$\mathrm{R}(\mathrm{g})$} \\
\hline $\begin{array}{l}\text { Tamanho de semente - TS } \\
(\mathrm{mm})\end{array}$ & \multicolumn{4}{|c|}{ Capacidade de Campo - CC (\%) } \\
\hline & 25 & 50 & 75 & 100 \\
\hline $12(\mathrm{P})$ & $0,0204 \mathrm{~A}$ & $0,0187 \mathrm{~B}$ & $0,0263 \mathrm{~B}$ & $0,0373 \mathrm{~A}$ \\
\hline $14(\mathrm{M})$ & $0,0233 \mathrm{~A}$ & $0,0297 \mathrm{~A}$ & $0,0268 \mathrm{~B}$ & $0,0339 \mathrm{~A}$ \\
\hline $16(\mathrm{G})$ & $0,0207 \mathrm{~A}$ & $0,0273 \mathrm{~A}$ & $0,0407 \mathrm{~A}$ & $0,0317 \mathrm{~B}$ \\
\hline DMS (Tukey a 5)\% & \multicolumn{4}{|c|}{0.0050} \\
\hline \multicolumn{5}{|c|}{ PAR $(g)$} \\
\hline \multirow[t]{2}{*}{$\mathrm{TS}(\mathrm{mm})$} & \multicolumn{4}{|c|}{ CC (\%) } \\
\hline & 25 & 50 & 75 & 100 \\
\hline $12(\mathrm{P})$ & $0,0748 \mathrm{~A}$ & $0,0793 \mathrm{~B}$ & $0,1034 \mathrm{~B}$ & $0,1236 \mathrm{~A}$ \\
\hline $14(\mathrm{M})$ & $0,0823 \mathrm{~A}$ & $0,0984 \mathrm{~A}$ & $0,1025 \mathrm{~B}$ & $0,1297 \mathrm{~A}$ \\
\hline $16(\mathrm{G})$ & $0,0793 \mathrm{~A}$ & $0,1012 \mathrm{~A}$ & $0,1169 \mathrm{~A}$ & $0,1294 \mathrm{~A}$ \\
\hline \multicolumn{5}{|l|}{ DMS (Tukey a 5\%) } \\
\hline \multicolumn{5}{|c|}{$\mathrm{C}(\mathrm{g})$} \\
\hline \multirow[t]{2}{*}{ TS (mm) } & \multicolumn{4}{|c|}{ CC (\%) } \\
\hline & 25 & 50 & 75 & 100 \\
\hline $12(\mathrm{P})$ & $0,0884 \mathrm{~A}$ & 0,0997B & $0,1376 \mathrm{C}$ & $0,1838 \mathrm{~A}$ \\
\hline $14(\mathrm{M})$ & $0,0963 \mathrm{~A}$ & $0,1246 \mathrm{~A}$ & $0,1522 \mathrm{~B}$ & $0,1838 \mathrm{~A}$ \\
\hline $16(\mathrm{G})$ & $0,0904 \mathrm{~A}$ & $0,1335 \mathrm{~A}$ & $0,1902 \mathrm{~A}$ & $0,1888 \mathrm{~A}$ \\
\hline DMS (Tukey a 5\%) & \multicolumn{4}{|c|}{0.0135} \\
\hline
\end{tabular}

*Médias com letras maiúsculas iguais nas colunas não deferem entre si pelo Teste de Tukey ao nível de 5\% de probabilidade.

os tamanhos de sementes testados e, posteriormente, seguida por $50 \%$ (Tabela 2). De acordo com Doneen e McGillivray (1943), a germinação das sementes de feijão vagem, ervilha e feijão Lima é afetada negativamente a partir de valores inferiores a $11 \%$ de umidade do solo. A diminuição na massa de matéria seca em função do déficit hídrico foi igualmente relatado por Pimentel e Perez (2000) e Gomes et al. (2000), para feijoeiro e por Moraes e Menezes (2003), Costa et al. (2004) e Moraes et al. (2005), para soja.

Para sementes grandes de faveira, houve um decréscimo linear na massa seca da raiz e parte aérea da plântula (Figura 4A-B) com a redução do nível de umedecimento após 30 dias de semeadura, porém a massa seca do cotilédone se manteve constante (Figura 4C). Enquanto, para as sementes médias, apenas a massa seca do cotilédone tiveram redução cúbica com a diminuição do nível de umedecimento e, no inverso, com o aumento de umedecimento, próximo de $100 \%$, houve aumento na massa seca dos cotilédones de faveira (Figura 4C).
Para sementes pequenas de faveira, o ponto de máxima para massa seca da raiz foi observado em 55,0\% de umedecimento, sendo que, a partir desse ponto, a massa seca da raiz diminuiu quadratidamente com a redução ou aumento do umedecimento (Figura 4A). Da forma semelhante, a redução na massa de matéria seca em função da falta de água foi observado por Gomes et al. (2000), para feijoeiro e, por Moraes et al. (2005), para soja.

De acordo com a Tabela 2, as sementes de grandes de faveira, seguida das médias, apresentaram desempenho semelhante, pois originaram as plântulas de maior massa de matéria seca. De forma geral, os resultados corroboram o descrito na literatura, pois as sementes maiores, por possuírem maior quantidade de reserva, para suprir os estádios inicias desenvolvimento, proporcionam a formação de plântulas mais pesadas (Popinigis, 1977; Carvalho e Nakagawa, 2000). De mesma forma, as sementes grandes de feijoeiro das cultivares Kaboon, Manteigão e Carioca proporcionam um 

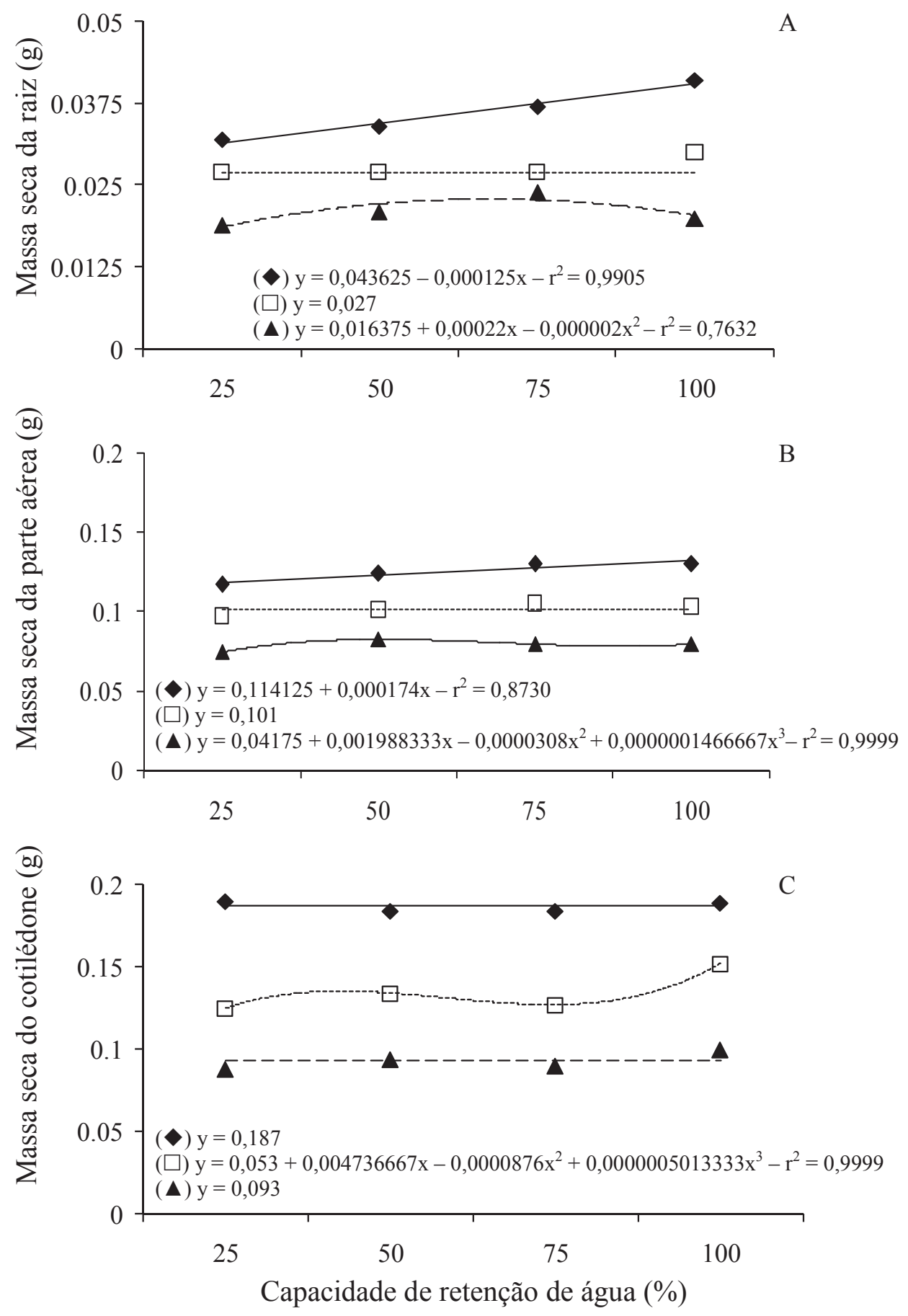

Figura 4. A. Massa seca da raiz. B. Massa seca da parte aérea. C. Massa seca do cotilédone de plântulas de faveira, oriundas de sementes das peneiras de $12(\Delta), 14(\square)$ e $16(\diamond) \mathrm{mm}$, após 30 dias de semeadura em em areia umedecida com $25,50,75$ e $100 \%$ da capacidade de retenção de água.

maior crescimento inicial da planta em relação à massa seca do caule, da raiz e massa seca total (Perin et al., 2002), assim como, as plântulas de Acacia senegal (L.) Willd. oriundas de sementes maiores, de acordo com Ferreira e Torres (2000), apresentaram quase o dobro do peso de matéria fresca daquelas originadas de sementes menores.

A exceção das plântulas de faveira desenvolvidas em $100 \%$ de umedecimento, as de sementes grandes em $75 \%$ 
possuem maior massa de matéria seca para as plântulas e para os cotilédones, assim como, a menor razão da parte aérea/raiz (RPA/R) e maior razão da (parte aérea + raiz)/ cotilédone (RPAR/C) (Tabela 3).

Para as sementes de 12 a $16 \mathrm{~mm}$, a RPA/R aumentou linearmente como aumento do nível de umedecimento. Enquanto, para sementes médias, a RPAP/C diminuiu linearmente com o aumento do umedecimento (Figura 5). De acordo com Barbosa et al. (1998), um sistema radicular maior aumenta a área de absorção de água e, por conseguinte, as plântulas com raízes bem desenvolvidas têm maiores chances de sobrevivência em campo, especialmente, sob limitação de água.

\section{CONCLUSÃO}

- A germinação das sementes de faveira não é afetada pelo tamanho de suas sementes, porém o vigor sim, sendo que as sementes grandes e médias originam plântulas mais vigorosas.

- O excesso de água reduz a germinação e, a falta, o crescimento das plântulas de faveira.

Tabela 3. Razão da parte aérea/raiz (RPA/R) e da (parte aérea + raiz)/cotilédone (RPAR/C) de plântulas de faveira de sementes pequena $(P)$, média $(M)$ e grande $(G)$ nas capacidades de campo de 25, 50,75 e $100 \%$ após 30 dias de semeadura.

\begin{tabular}{|c|c|c|c|c|}
\hline \multicolumn{5}{|c|}{ RPA/R (g/g) } \\
\hline \multirow[t]{2}{*}{ Tamanho de semente - TS (mm) } & \multicolumn{4}{|c|}{ Capacidade de Campo - CC (\%) } \\
\hline & 25 & 50 & 75 & 100 \\
\hline $12(\mathrm{P})$ & $3,561 \mathrm{~A}$ & $4,253 \mathrm{~A}$ & $3,932 \mathrm{~A}$ & $3,336 \mathrm{~B}$ \\
\hline $14(\mathrm{M})$ & $3,566 \mathrm{~A}$ & $3,326 \mathrm{~B}$ & $3,886 \mathrm{~A}$ & $3,859 \mathrm{AB}$ \\
\hline $16(\mathrm{G})$ & $3,849 \mathrm{~A}$ & $3,707 \mathrm{~B}$ & $2,890 \mathrm{~B}$ & $4,101 \mathrm{~A}$ \\
\hline DMS (Tukey a 5\%) & \multicolumn{4}{|c|}{0.5314} \\
\hline \multicolumn{5}{|c|}{$\mathrm{RPAR} / \mathrm{C}(\mathrm{g} / \mathrm{g})$} \\
\hline \multirow[t]{2}{*}{$\mathrm{TS}(\mathrm{mm})$} & \multicolumn{4}{|c|}{$\mathrm{CC}(\%)$} \\
\hline & 25 & 50 & 75 & 100 \\
\hline $12(\mathrm{P})$ & $1.2726 \mathrm{~A}$ & $0.9910 \mathrm{~B}$ & $0.9450 \mathrm{~B}$ & $0.8759 \mathrm{~A}$ \\
\hline $14(\mathrm{M})$ & $1.1001 \mathrm{~B}$ & $1.3023 \mathrm{~A}$ & $0.8501 \mathrm{~B}$ & $0.8969 \mathrm{~A}$ \\
\hline $16(\mathrm{G})$ & $1.1079 \mathrm{~B}$ & $0.9623 \mathrm{~B}$ & $1.3495 \mathrm{~A}$ & $0.8647 \mathrm{~A}$ \\
\hline DMS (Tukey a 5\%) & \multicolumn{4}{|c|}{0.1312} \\
\hline
\end{tabular}

*Médias com letras maiúsculas iguais nas colunas não deferem entre si pelo Teste de Tukey ao nível de 5\% de probabilidade.

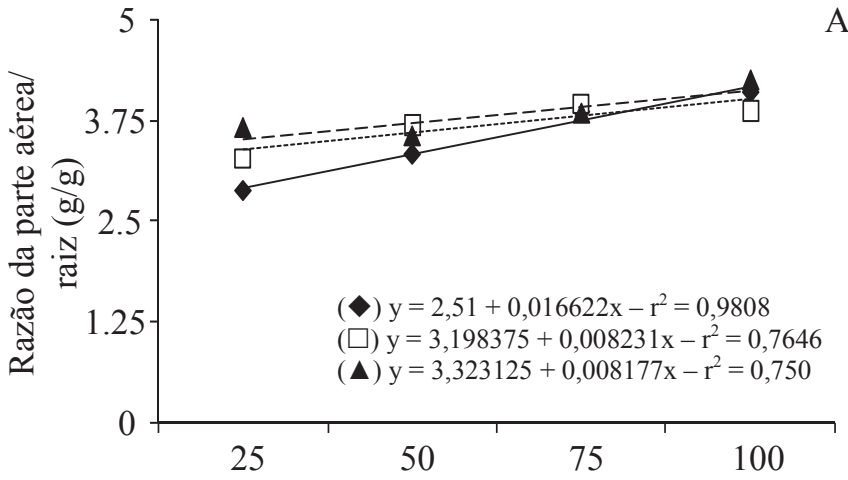

Capacidade de retenção de água $(\%)$

A

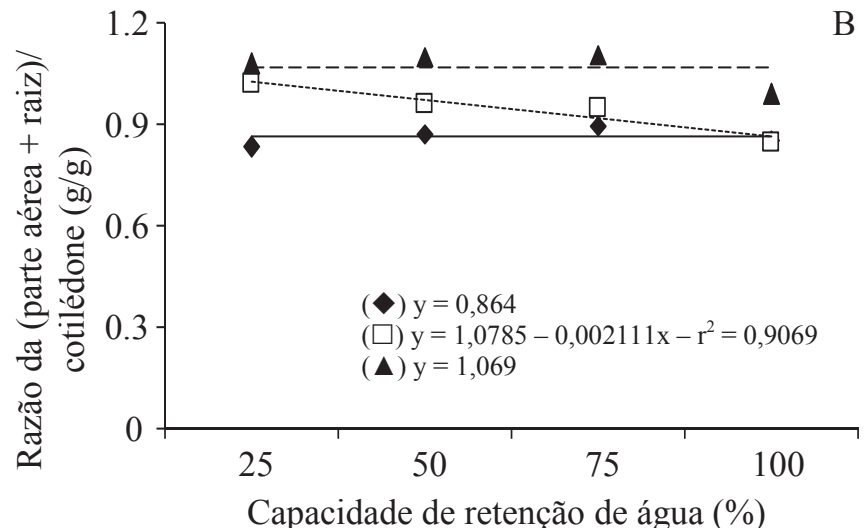

Figura 5. A. Razão da parte aérea/raiz (RPA/R). B. Razão da (parte aérea + raiz)/cotilédone (RPAR/C) de plântulas de faveira, oriundas de sementes das peneiras de $12(\Delta), 14(\square)$ e $16(\diamond) \mathrm{mm}$, após 30 dias de semeadura em areia umedecida com $25,50,75$ e $100 \%$ da capacidade de retenção de água. 


\section{AGRADECIMENTOS}

À Sra. Maria M. da Silva e ao Sr. Josias G. Silva pelo empenho na coleta e envio de sementes de faveira provenientes de Macapá, AP, Brasil.

\section{REFERÊNCIAS}

AGUIAR, I.B.; PIÑA-RODRIGUES, F.C.M; FIGLIOLIA, M.B.. Sementes Florestais Tropicais, ABRATES, Brasília, 350p. 1993.

ARAÚJO-NETO, J.C.; AGUIAR, I.B.; FERREIRA, V.M.. Efeito da temperatura e da luz na germinação de sementes e Acacia polyphylla DC.. Revista Brasileira de Botânica. São Paulo, v. 26, n. 2, p. 249-256. 2003.

BARBOSA, A.P.; UCHIDA, T.; CAMPOS, M.A.A.; MARQUES, A.J.S. Tecnologia da produção de mudas de espécies florestais. In: HIGUCHI, N.; CAMPOS, M.A.A.; SAMPAIO, P.T.B; SANTOS, J. (Eds.). Pesquisas florestais para conservação da floresta e reabilitação de áreas degradadas da Amazônia. Manaus - AM: Instituto Nacional de Pesquisas da Amazônia - INPA, 1998, p. 216-252.

BARTLETT, M.S. The Use of Transformations. Biometrics, England, v. 3, p. 39-52. 1947.

BENINCASA, M.M.P.. Análise do Crescimento em Plantas - Noções Básicas. Jaboticabal: FUNESP, 42p. 2003.

BEWLEY, J.D.; BLACK, M. Seed Physiology of Development and Germination. $2^{\circ}$ Ed. New York and London. Plenum Press. 1994. 657p.

BORGES, E.E.L.; RENA, A.B. Germinação de sementes. In: AGUIAR,I.B.; PIÑA-RODRIGUES, F.C.M.; FIGLIOLIA, M.B. Sementes florestais tropicais. Brasília, ABRATES, p. 83-135, 1993.

BRACCINI, A.L.; REIS, M.S.; SEDIYAMA, C.S.; SCAPIM, C.A.; BRACCINI, M.C.L. Avaliação da qualidade fisiológica de sementes de soja após o processo de hidratação-desidratação e envelhecimento acelerado. Pesquisa Agropecuária Brasileira. Brasília, v. 34, n. 6, p. 1053-1066, 1999.

BRASIL. Ministério da Agricultura e Reforma Agrária. Regras para Análise de Sementes. Brasília, 1992. 365p.

CARDOSO, V.J.M Germinação. In: KERBAUY, G.B. (Org.). Fisiologia Vegetal. Rio de Janeiro - RJ: Editora Guanabara Koogan. p. $386-408$.

CARNEIRO, M.A.C.; SIQUEIRA, J.O.; MOREIRA, F.M.S; CARVALHO, D.; BOTELHO, S.A. JUNIOR, O.J.S.
Micorriza arbuscular em espécies arbóreas e arbustivas de ocorrência no sudeste do Brasil. CERNE, Lavras, v. 4, n.1, p.129-145, 1998.

CARPANEZZI, A. A. Seleção de espécies florestais para utilização em terras marginais e degradadas. Colombo: EMBRAPA-CNPF, 1993. 58p.

CARVALHO,N.M.Efeitodotamanhosobreocomportamento de sementes de amendoim (Arachis hypogea L.). Ciência e Cultura, Campinas, v. 24, n. 1, p. 64-69, 1972.

CARVALHO, N.M.; NAKAGAWA, J. Sementes: Ciência, Tecnologia e Produção. $4^{\circ}$ Ed. Jaboticabal-SP: FUNEP, 2000, 588p.

CASTRO, R.D.; BRADFORD, K.J.; HILHORST, H.W.M. Embebição e reativação do metabolismo. In: FERREIRA, A.G.; BORGHETTI, F. (Orgs.). Germinação de Sementes: Do básico ao aplicado. Porto Alegre - RS: Editora Artmed, p. 149-162, 2004.

COSTA, P.R.; CUSTÓDIO, C.C, MACHADO-NETO, N.B.; MARUBAYASHI, O.M. Estresse hídrico induzido por manitol em sementes de soja de diferentes tamanhos. Revista Brasileira de Sementes, Pelotas, v. 26, n. 1, p. 105-113, 2004.

CRUZ, E.D.; MARTINS, F.O.; CARVALHO, J.E.U. Biometria de frutos e sementes e germinação de jatobácuruba (Hymenaea intermedia Ducke, Leguminosae Caesalpinioideae). Revista Brasileira de Botânica, Brasilia, v.24, p.161-165, 2001.

D'ARCO, E.; MATTEI, V.L. Efeitos do preparo localizado do solo, protetor físico e material de cobertura na sobrevivência de plantas de Pinus taeda L. em semeadura direta. Revista Científica Rural, Bagé, v. 5, n. 2, p. 50-58, 2000.

DONNEN, L.D.; McGILLVRAY, J.H. Germination (emergence) of vegetable seed as affected by different soil moisture conditions. Plant Physiology, Lancaster, v. 18, p. $524-529,1943$.

DURYEA, M.L. Forest regeneration methods: natural regeneration, direct seeding and planting. Circular 759, Florida Cooperative Extension Service, Institute of Food and Agricultural Sciences, University of Florida. 2000. 13p.

FERREIRA, C.A.G. Recuperação de áreas degradadas. Informe Agropecuário, Belo Horizonte, v. 21, n. 202, p. 127-130, 2000 .

FERREIRA, M.G.R; TORRES, S.B. Influência do tamanho das sementes na germinação e no vigor de plântulas de Acacia senegal (L.) Willd. Revista Brasileira de Sementes, Pelotas, v. 22, n. 1, p.271-275, 2000.

FIGLIOLIA, M.B.. Colheita de Sementes. In: SILVA, A.; 
PIÑA-RODRIGUES, F.C.M.; FIGLIOLIA, M.B. (Orgs.) Manual Técnico de Sementes Florestais. São Paulo - SP. 14: p. 1-12. 1995.

FIGLIOLIA, M.B.; AGUIAR, I. B.. Secagem, extração e beneficiamento de sementes. In: AGUIAR, I.B.; PIÑARODRIGUES, F.C.M.; FIGLIOLIA, M.B.. (Orgs.). Sementes florestais tropicais. 1 ed. Brasília - DF, 1993, p. 303-331.

FLORIANO, E. P. Germinação e Dormência de Sementes Florestais. In: Caderno Didático $n^{\circ} 2.1$ Ed., Santa Rosa RS: ANORGS. 2004. 19p.

FORTES, J.L.O. Reabilitação de depósito de rejeito de refino de bauxita com uso de resíduos industriais e leguminosas arbóreas. Rio de Janeiro - RJ. 2000. 184p. Tese de Doutorado- Universidade Federal Rural do Rio do Janeiro - UFRRJ.

FRANCO, A.A.; CAMPELOLO, E.F.C; SILVA, E.M.R; FARIA, S.M. Revegetação de solos degradados: Seropédica. In: Comunicado Técnico, Brasília: EMBRAPA-CNPBS, 1992, 8p.

GOMES, A.A.; ARAÚJO, A.D.; ROSSIELLO, R.O.P.; PIMENTEL, C. Acumulação de biomassa, características fisiológicas e rendimento de grãos de feijoeiro irrigado e sob sequeiro. Pesquisa Agropecuária Brasileira, Brasília, v.35, n.10, p.1927-1937, 2000 .

HAIG, D.; WESTOBY, M. Seed size, pollination casts and angiosperm success. Evolutionary Ecology, London, v. 5, p. 231-247, 1991.

IBM - INSTITUTO BRASILEIRO DE MINERAÇÃO. Mineração e meio ambiente. Brasília, 1992. 126p.

JANKOVSKI, T. Estudo de alguns aspectos da regeneração natural induzida em povoamentos de Pinus taeda $\mathbf{L}$. e Pinus elliotti Engelm. 1996. 129p. Tese de doutorado Universidade Federal do Paraná, Curitiba, 1996.

LAURANCE, W.F., FERREIRA, L.V., RANKINDE MERONA,.M.,LAURANCE, S.G., HUTCHINGS, R.G.; LOVEJOY, T.E. Effects of forest fragmentation on recruitment patterns in Amazonian tree communities. Conservation Biology. USA, n. 12, p. 460-464. 1998.

LIMA, J.D.; SILVA, B.M.S.; MORAES, W.S. Germinação e armazenamento de sementes de Virola surinamensis (Rol.) Warb. (Myristicaceae).. Revista Árvore. Viçosa, v. 31, n. 1, p. 37-42, 2007.

LORENZI, H.. Árvores Brasileiras: Manual de Identificação e Cultivo de Plantas Arbóreas Nativas do Brasil. Nova Odessa - SP: Editora Plantarum, 1 Ed., 1992. 352p.
MAGUIRE, J. D. Speed of germination aid in selection and evaluation for emergence and vigour. Crop Science, Madison, v. 2, n. 2, p. 176-177, 1962.

MALAVASI, U. C.; MALAVASI, M. M. Influencia do tamanho da semente na germinação e no estabelecimento de espécies de diferentes estágios da sucessão vegetal. Floresta e Ambiente, Seropédica, v. 8, n. 1, p. 211-215. 2001.

MARCOS-FILHO, J. Fisiologia de Sementes de plantas cultivadas. Piracicaba: Fealq, 2005, 495p.

MARCOS-FILHO, J. Germinação de sementes. In: SEMANA DE ATUALIZAÇÃO EM PRODUÇÃO DE SEMENTES, 1, Piracicaba - SP, 1986. Trabalhos apresentados. Campinas: Fundação Cargill, 1986. p.11-39.

MARCOS-FILHO, J.; CICERO, S.M. \& SILVA, W.R. Avaliação da qualidade fisiológica das sementes. Piracicaba: FEALQ, 1987. 230p

MATTEI, V.L. ROSENTHAL, M. D'AVILA. Semeadura direta de canafístula (Peltophorum dubium (Spreng.)Taub. no enriquecimento de capoeiras. Revista Árvore, Viçosa, v. 26, n. 6, p. 649-654, 2002.

MENEGHELlO, G.E.; MATTEI, V.L. Semeadura direta de Timbaúva (Enterolobium contortisiliquum), Canafístula (Peltophorum dubium) e Cedro (Cedrela fissilis) em campos abandonados. Ciência Florestal, Santa Maria, v. 14, n. 2, p. 21-27, 2004.

MORAES, G.A.F; MENEZES, N.L. Desempenho de sementes de soja sob condições diferentes de potencial osmótico. Ciência Rural, Santa Maria, v. 33, n. 2, p. 219226, 2003.

MORAES, G.A.F; MENEZES, N.L.; PASQUALLI, L.L. Comportamento de sementes de feijão sob diferentes potenciais osmóticos. Ciência Rural, Santa Maria - PR: v.35, n.4, p.776-780, 2005.

NÓBREGA, L.H.P.; AMARAL, A.L.P.; SADER, R. Qualidade fisiológica de sementes de amendoim de diferentes tamanhos e densidades. Revista Brasileira de Sementes, Brasília, v. 16, n. 1, p. 80-84, 1994.

PAULA, J.E.; ALVES, J.L.H.. Madeiras Nativas: Anatomia, dendrologia, dendrometria, produção e uso. Brasília : Fundação Mokiti Okada-MOA. 1997. 543 p.

PERIN, A.; ARAÚJO, A.P.; TEIXEIRA, M.G. Efeito do tamanho da semente na acumulação de biomassa e nutrientes e na produtividade do feijoeiro. Pesquisa Agropecuária Brasileira, Brasília, v. 37, n. 12, p. 1711-1718, 2002.

PIMENTEL, C.; PEREZ. A.J. DE LA C. Estabelecimento de parâmetros para avaliação de tolerância à seca, em genótipos 
de feijoeiro. Pesquisa Agropecuária Brasileira, Brasília, v. 35 , n. 1 , p. 31-39, 2000.

PIMENTEL-GOMES, F. P. Curso de Estatística Experimental. Piracicaba - SP: Nobel. 1987. 467p.

POPINIGIS, F. Fisiologia de Semente. $1^{\circ}$ Ed.. AGIPLAN. Editora Brasília, 1977. 289 p.

PORTELA, R.C.Q.; SILVA, I.L.; PINÃ-RODRIGUES, F.C.M. Crescimento inicial de mudas de Clitoria fairchildiana Howard E Peltophorum dubium (Sprenge) Taub em diferentes condições de sombreamento. Ciência Florestal, Santa Maria, v. 11, n. 2, p. 163-170, 2001.

RODRIGUES, R.R.; GANDOLFI, S. Conceitos, tendências e ações para recuperação de florestas ciliares. In: RODRIGUES, R.R.; LEITÃO-FILHO, H.F. Matas ciliares (conversação e recuperação), São Paulo: EDUSP/FAPESP, 2000, p. 235-247.

SAMPAIO, E. The effects of fragmentation on structure and diversity of bat communties in a central Amazonian tropical rain forest. $2000.124 \mathrm{p}$. Ph.D. Thesis - University of Tübingen, Tübingen, DE.

SILVA, A.F.; OLIVEIRA,. R.V.; SANTOS, N.R.L.; PAULA, A. Um trecho de floresta semidecídua submontana da Fazenda São Geraldo, Viçosa - MG. Revista Árvore, Viçosa, v. 27, n. 3, p. 311-319, 2003.

SILVA, B. M. S., MÔRO, F. V., SADER, R., CESARINO, F. Aspectos morfológicos da sementes de Clitoria fairchildiana R. A. Howard (Fabaceae). In: XIV Congresso Brasileiro de Sementes, 2005, Foz do Iguaçu - PR.

SOUTO, R.N.P. Sazonalidade de culicídeos (Díptera, Culicidae) e tentativas de isolamento de arbovírus em floresta e savana no Estado do Amapá, Brasil. 1994. 158 p. Dissertação de Mestrado - UFPA/MPEG, Belém - PA.

WETZEL, C.T. Some effects of seed size on perfomance of soybeans (Glycine max L. Merrill.). 1975. 98p. Dissertation, Ph.D. - Mississipi State University. Miss, State.

WHITE, J. W.; GONZÁLEZ, A. Characterization of the negative association between seed yield and seed size among genotypes of common bean. Field Crops Research, USA, v. 23, p. $159-175,1990$.

ZANON, A.; CARPANEZZI, A.A.; FOWLER, J.A.P. Germinação em laboratório e armazenamento de sementes de Tarumã-Branco (Citharexylum myrianthum CHAM.). Boletim de Pesquisa Florestal, Colombo, n. 35, p.75-82. 1997. 